\title{
Analisis Kualitas Pelayanan terhadap Kepuasan Masyarakat atau Pasien di RSUD Tengku Rafi'an Kabupaten Siak Menggunakan Metode Importance Performance Analysis dan Potential Gain in Customer Value
}

\author{
Dewi Diniaty $^{1}$, Rusnilawati ${ }^{2}$ \\ ${ }^{1,2}$ Jurusan Teknik Industri, Fakultas Sains dan Teknologi, UIN Sultan Syarif Kasim Riau \\ Jl. HR. Soebrantas No. 155 Simpang Baru, Panam, Pekanbaru, 28293 \\ Email: dewidiniaty@uin-suska.ac.id, rusnilazara@gmail.com
}

\begin{abstract}
Abstrak
RSUD Tengku Rafi'an Kabupaten Siak merupakan satu-satu nya rumah sakit yang ada di Kabupaten Siak. Karena keterbatasan rumah sakit di Kabupaten Siak maka banyak masyarakat yang berobat di RSUD Tengku Rafi'an Kabupaten Siak. Namun setelah masyarakat berobat di RSUD Tengku Rafi'an Kabupaten Siak, terdapat beberapa keluhan masyarakat tentang pelayanan yang diberikan oleh pihak rumah sakit. Penelitian ini bertujuan untuk mengetahui tingkat kesesuaian antara kepentingan (Importance) dan kepuasan (Satisfaction) pasien terhadap kinerja (Performance) kualitas pelayanan RSUD Tengku Rafi'an Kabupaten Siak dan menganalisis atribut-atribut yang menjadi prioritas perbaikan layanan berdasarkan metode Potential Gain in Customer Value (PGCV) dalam meningkatkan kualitas pelayanan RSUD Tengku Rafi'an Kabupaten Siak. Dari hasil pengolahan data didapatkan bahwa terdapat enam urutan prioritas perbaikan kualitas yang harus dilakukan oleh RSUD Tengku Rafi'an Kabupaten Siak berdasarkan metode IPA dan PGCV yaitu ruangan di rumah sakit memiliki peralatan yang lengkap, dokter memberikan waktu pelayanan yang cukup memuaskan pasien, rumah sakit memiliki papan petunjuk yang jelas, WC Rumah sakit bersih, rumah sakit memiliki ruang tunggu yang nyaman, serta tenaga medis dan petugas lainnya membantu jika ada permasalahan pasien.
\end{abstract}

Kata Kunci: Importance Performance Analysis, Kualitas Pelayanan, Potential Gain in Customer Value

\section{Pendahuluan}

Rumah Sakit menjadi ujung tombak pembangunan dan pelayanan kesehatan masyarakat, namun tidak semua rumah sakit yang ada di Indonesia memiliki standar pelayanan dan kualitas yang sama. Semakin banyaknya rumah sakit di Indonesia serta semakin tingginya tuntutan masyarakat akan fasilitas kesehatan yang berkualitas dan terjangkau, rumah sakit harus berupaya survive di tengah persaingan yang semakin ketat sekaligus memenuhi tuntutan-tuntutan pasien. Hal itu menjadi salah satu dasar rumah sakit untuk memberikan pelayanan prima pada setiap jenis pelayanan yang diberikan baik untuk pelayanan rawat jalan, pelayanan rawat inap maupun pelayanan gawat darurat (Saragih dkk, 2013).

Harapan pasien, mereka akan mendapatkan semua kebutuhannya. Dengan terpenuhinya kebutuhan pasien mereka akan merasa puas dan akan loyal dengan rumah sakit, namun tenaga kesehatan sering tidak menyadari bahwa pelayanan akan kebutuhan pasien sudah merupakan dimensi dari mutu pelayanan (Saragih dkk, 2013).
RSUD Tengku Rafi'an Kabupaten Siak merupakan satu-satu nya rumah sakit yang ada di Kabupaten Siak. Karena keterbatasan rumah sakit di Kabupaten Siak banyak masyarakat yang berobat di RSUD Tengku Rafi'an Kabupaten Siak. Namun setelah masyarakat berobat di RSUD Tengku Rafi'an Kabupaten Siak, banyak sekali keluhan masyarakat tentang pelayanan yang diberikan oleh pihak rumah sakit. Sehingga banyak masyarakat yang merasa tidak nyaman seperti panasnya ruang tunggu di RSUD Tengku Rafi'an, ada juga masyarakat yang merasa tidak puas apabila berobat di RSUD Tengku Rafi'an Kabupaten Siak di karenakan oleh kurangnya pelayanan dokter terhadap pasien dan banyak juga masyarakat yang memilih untuk berobat ke Pekanbaru. Sebagai pihak yang memberikan pelayanan jasa kepada masyarakat, pihak rumah sakit seharusnya memperhatikan tingkat kepuasan dan kualitas pelayanan yang diberikan, agar pasien merasa puas dan nyaman untuk berobat di RSUD Tengku Rafi'an Kabupaten Siak.

Metode Importance-Performance Analysis (IPA) adalah suatu metode yang di gunakan untuk melihat tingkat kepuasan pasien dan masyarakat 
terhadap pelayanan yang diberikan RSUD Tengku Rafi'an dan untuk melihat harapan pasien atau masyarakat terhadap pelayanan RSUD, sehingga dengan ada nya metode IPA ini dapat dilihat atributatribut yang penting bagi pasien atau masyarakat akan tetapi kinerja RSUD Tengku Rafi'an kurang memuaskan, sehingga dapat diperbaiki agar pasien atau masyarakat merasa puas terhadap RSUD Tengku Rafi'an. Metode Potential Gain In Customer Value (PGCV) adalah suatu metode yang digunakan untuk menganalisis prioritas perbaikan dari atributatribut yang penting sedangkan kinerjanya kurang, sehingga dengan metode PGCV ini dapat diketahui atribut-atribut yang harus diperbaiki pertama, kedua dan seterusnya. Dengan demikian kedua metode di atas cocok digunakan dalam penelitian ini, kedua metode di atas akan dikorelasi untuk mengetahui atribut-atribut yang diprioritaskan untuk diperbaiki. Pada penelitian sebelumnya peneliti hanya menggunakan satu metode saja, pada penelitian ini peneliti melakukan penggabungan dua metode agar prioritas perbaikan yang paling diutamakan atau prioritas perbaikan yang pertama dilakukan dapat diketahui dengan jelas.

\section{Metode Penelitian}

Metodologi digunakan untuk mengarahkan dan mempermudah proses analisis dalam mencari solusi dalam memecahkan masalah dan merancang manajemen penelitian secara baik. Berikut merupakan susunan metodologi penelitian yang digunakan.

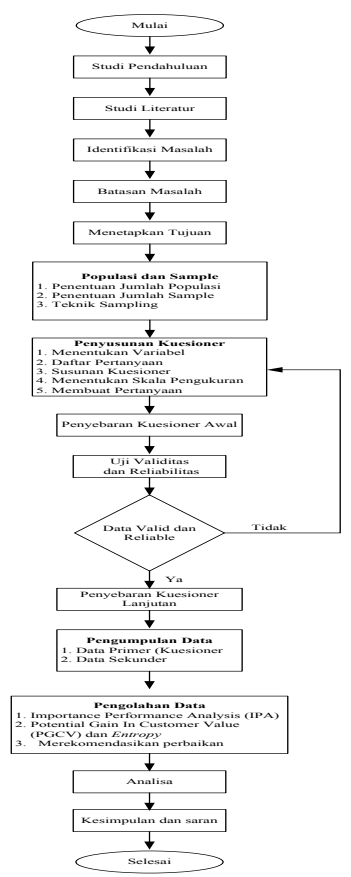

Gambar 1. Flow Chart Metode Penelitian

\section{Hasil dan Pembahasan}

Rumah Sakit Umum Daerah Siak merupakan salah satu unit kerja yang sudah mempunyai struktur sendiri sejak Januari 2009, awal berdirinya tahun 2001 dengan melaksanakan pelayanan di bangunan Puskesmas Siak Jalan Sultan Syarif Hasyim.

Sejak Tahun 2005 RSUD Siak sudah menempati Gedung baru yang terletak di Jalan Raja Kecik No. 01 Siak Sri Indrapura. Pada tahun 2009 RSUD Siak telah mendapat izin operasional tetap dari Departemen Kesehatan sesuai dengan SK Menkes: HK.07.06/III/2231/08 tanggal 27 Juni 2008 dan RSUD Siak telah ditetapkan menjadi Rumah Sakit Umum Daerah Tipe C sesuai Surat Keputusan Menteri Kesehatan nomor

776/MENKES/SK/VIII/2008 tanggal 19 Agustus 2008. Sejak September Tahun 2011 RSUD Siak sudah terakreditasi.

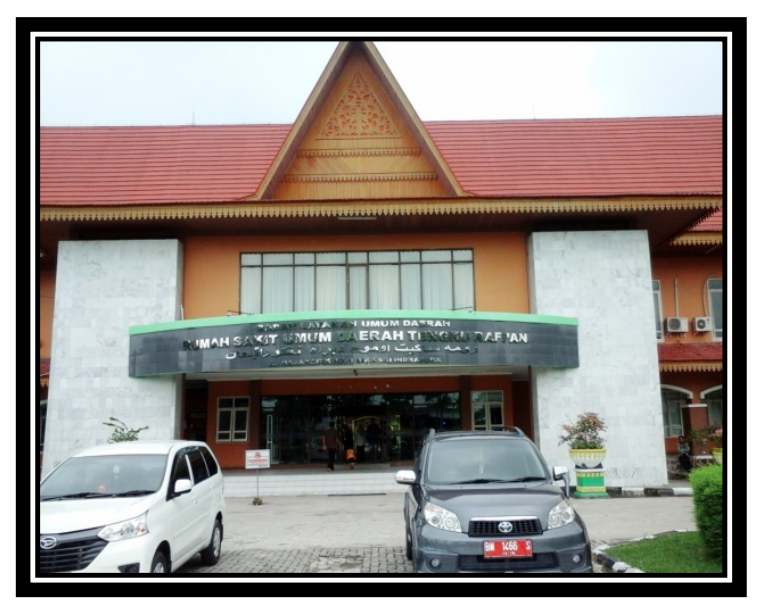

Gambar 2. RSUD Tengku Rafi'an Kabupaten Siak

\section{Uji Validitas}

Uji validitas dilakukan untuk melihat apakah kuesioner yang disebarkan bersifat validitas, untuk melihat validitas kuesioner pada penelitian ini menggunakan software SPSS 17.0 for Windows. Rumus menghitung validitas kuesioner secara manual adalah sebagai berikut: $r=\frac{N\left(\sum X Y\right)-\left(\sum X \cdot \sum Y\right)}{\sqrt{\left[N \sum X^{2}\right]\left[n \sum Y^{2}-\left(\sum Y\right)^{2}\right]}}$

Berikut ini adalah hasil dari uji validitas yang dilakukan dengan menggunakan software SPSS 17.0 for Windows. 
Tabel 1. Rekapitulasi Uji Validitas Untuk Kinerja/Kenyataan

\begin{tabular}{|c|c|c|c|c|}
\hline Dimensi & $\begin{array}{c}\text { No } \\
\text { Pernyata } \\
\text { an }\end{array}$ & $\begin{array}{c}\text { Correcte } \\
\text { d Item } \\
\text { Total } \\
\text { Correlati } \\
\text { on }\end{array}$ & $\begin{array}{c}\text { R_Tabel } \\
\text { Dengan } \\
\text { Taraf } \\
\text { Signifika } \\
5 \%\end{array}$ & $\begin{array}{c}\text { Ketera } \\
\text { ngan }\end{array}$ \\
\hline \multirow{6}{*}{ TANGIBLE } & 1 & 0,575 & 0,176 & Valid \\
\hline & 2 & 0,677 & 0,176 & Valid \\
\hline & 3 & 0,609 & 0,176 & Valid \\
\hline & 4 & 0,510 & 0,176 & Valid \\
\hline & 5 & 0,627 & 0,176 & Valid \\
\hline & 6 & 0,485 & 0,176 & Valid \\
\hline \multirow{5}{*}{ ЕМРНАТY } & 7 & 0,715 & 0,176 & Valid \\
\hline & 8 & 0,784 & 0,176 & Valid \\
\hline & 9 & 0,847 & 0,176 & Valid \\
\hline & 10 & 0,768 & 0,176 & Valid \\
\hline & 11 & 0,761 & 0,176 & Valid \\
\hline \multirow{4}{*}{$\begin{array}{l}\text { RELIABI } \\
\text { LITY }\end{array}$} & 12 & 0,804 & 0,176 & Valid \\
\hline & 13 & 0,822 & 0,176 & Valid \\
\hline & 14 & 0,743 & 0,176 & Valid \\
\hline & 15 & 0,742 & 0,176 & Valid \\
\hline \multirow{6}{*}{$\begin{array}{l}\text { RESPON } \\
\text { SIVNESS }\end{array}$} & 16 & 0,823 & 0,176 & Valid \\
\hline & 17 & 0,789 & 0,176 & Valid \\
\hline & 18 & 0,703 & 0,176 & Valid \\
\hline & 19 & 0,789 & 0,176 & Valid \\
\hline & 20 & 0,744 & 0,176 & Valid \\
\hline & 21 & 0,810 & 0,176 & Valid \\
\hline \multirow{4}{*}{$\begin{array}{c}\text { ASSURAN } \\
C E\end{array}$} & 22 & 0,815 & 0,176 & Valid \\
\hline & 23 & 0,746 & 0,176 & Valid \\
\hline & 24 & 0,773 & 0,176 & Valid \\
\hline & 25 & 0,666 & 0,176 & Valid \\
\hline
\end{tabular}

(Sumber: Pengolahan Data SPSS 17.0 For Windows, 2016)

Tabel 2. Rekapitulasi Uji Validitas Untuk Kepentingan/Harapan

\begin{tabular}{|c|c|c|c|c|}
\hline \multirow{7}{*}{ Dimensi } & $\begin{array}{c}\text { No } \\
\text { Pernyata } \\
\text { an }\end{array}$ & $\begin{array}{c}\text { Correcte } \\
\text { d Item } \\
\text { Total } \\
\text { Correlati } \\
\text { on }\end{array}$ & $\begin{array}{c}\text { R_Tabel } \\
\text { Dengan } \\
\text { Taraf } \\
\text { Signifika } \\
5 \%\end{array}$ & $\begin{array}{c}\text { Ketera } \\
\text { ngan }\end{array}$ \\
\hline \multirow{5}{*}{ TANGIBLE } & 1 & 0,387 & 0,176 & Valid \\
\cline { 2 - 6 } & 2 & 0,477 & 0,176 & Valid \\
\cline { 2 - 6 } & 3 & 0,601 & 0,176 & Valid \\
\cline { 2 - 6 } & 5 & 0,488 & 0,176 & Valid \\
\cline { 2 - 6 } & 5 & 0,359 & 0,176 & Valid \\
\hline
\end{tabular}

(Sumber: Pengolahan Data SPSS 17.0 For Windows, 2016)
Tabel 2. Rekapitulasi Uji Validitas Untuk Kepentingan/Harapan (lanjutan)

\begin{tabular}{|c|c|c|c|c|}
\hline Dimensi & $\begin{array}{c}\text { No } \\
\text { Pernyata } \\
\text { an }\end{array}$ & $\begin{array}{c}\text { Correcte } \\
\text { d Item } \\
\text { Total } \\
\text { Correlati } \\
\text { on }\end{array}$ & $\begin{array}{c}\text { R_Tabel } \\
\text { Dengan } \\
\text { Taraf } \\
\text { Signifika } \\
5 \%\end{array}$ & $\begin{array}{c}\text { Ketera } \\
\text { ngan }\end{array}$ \\
\hline & 6 & 0,574 & 0,176 & Valid \\
\hline \multirow{5}{*}{ ЕМРНАTY } & 7 & 0,357 & 0,176 & Valid \\
\hline & 8 & 0,614 & 0,176 & Valid \\
\hline & 9 & 0,570 & 0,176 & Valid \\
\hline & 10 & 0,442 & 0,176 & Valid \\
\hline & 11 & 0,592 & 0,176 & Valid \\
\hline \multirow{4}{*}{$\begin{array}{c}\text { RELIABI } \\
\text { LITY }\end{array}$} & 12 & 0,576 & 0,176 & Valid \\
\hline & 13 & 0,529 & 0,176 & Valid \\
\hline & 14 & 0,338 & 0,176 & Valid \\
\hline & 15 & 0,597 & 0,176 & Valid \\
\hline \multirow{6}{*}{$\begin{array}{l}\text { RESPON } \\
\text { SIVNESS }\end{array}$} & 16 & 0,466 & 0,176 & Valid \\
\hline & 17 & 0,576 & 0,176 & Valid \\
\hline & 18 & 0,408 & 0,176 & Valid \\
\hline & 19 & 0,373 & 0,176 & Valid \\
\hline & 20 & 0,544 & 0,176 & Valid \\
\hline & 21 & 0,391 & 0,176 & Valid \\
\hline \multirow{4}{*}{$\begin{array}{c}A S S U R A N \\
C E\end{array}$} & 22 & 0,374 & 0,176 & Valid \\
\hline & 23 & 0,490 & 0,176 & Valid \\
\hline & 24 & 0,663 & 0,176 & Valid \\
\hline & 25 & 0,622 & 0,176 & Valid \\
\hline
\end{tabular}

(Sumber: Pengolahan Data SPSS 17.0 For Windows, 2016)

\section{Uji Reliabilitas}

Uji reliabilitas adalah untuk melihat kehandalan dari sebuah kuesioner, maksudnya adalah kuesioner ini dapat digunakan secara berulang-ulang. Uji reliabilitas untuk kenyataan adalah 0,760 , artinya kuesioner penelitian untuk kenyataan reliabel (handal), dan uji reliabilitas untuk kepentingan adalah 0,737 , artinya kuesioner penelitian untuk kepentingan reliabel (handal).

\section{Importance Performance Analysis (IPA)}

Important Performance Analysis dilakukan dengan menghitung skor total kinerja pelayanan dan kepentingan/kepentingan pasien rumah sakit. Selanjutnya dilakukan perhitungan nilai $X$ (rata-rata skor kinerja) dan $Y$ (rata-rata skor kepentingan) yang akan dipetakan dalam diagram kartesius.

Hasil perhitungan rata-rata skor kinerja dan kepentingan akan dijabarkan dan dibagi menjadi empat bagian kedalam diagram kartesius. Untuk secara jelasnya ditujukan pada Gambar 3: 


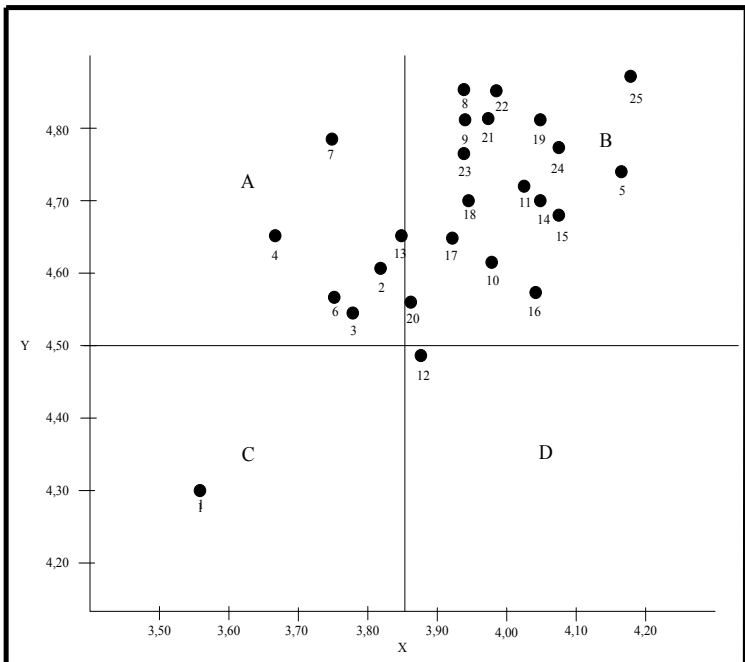

Gambar 3. Diagram Kartesius

Dari Gambar 3. dapat dilihat atribut-atribut yang berada pada masing-masing kuadran. Atribut yang terdapat pada kuadran A dapat dilihat pada Tabel 3 sebagai berikut:

Tabel 3 Atribut Pernyataan pada Kuadran A

\begin{tabular}{|c|c|c|c|c|c|c|}
\hline No & $\begin{array}{c}\text { Atribut } \\
\text { Pernyataan }\end{array}$ & Dimensi & TK & $\mathrm{A} / \mathrm{H}$ & $\mathrm{X}$ & $\overline{\mathrm{y}}$ \\
\hline 2 & $\begin{array}{l}\text { Rumah sakit } \\
\text { memiliki } \\
\text { ruang tunggu } \\
\text { yang nyaman }\end{array}$ & Tangible & 82,81 & A & 3,82 & 4,61 \\
\hline 3 & $\begin{array}{l}\text { WC Rumah } \\
\text { sakit bersih }\end{array}$ & Tangible & 83,27 & A & 3,78 & 4,54 \\
\hline 4 & $\begin{array}{l}\text { Ruangan di } \\
\text { Rumah sakit } \\
\text { memiliki } \\
\text { peralatan } \\
\text { yang lengkap }\end{array}$ & Tangible & 78,90 & A & 3,68 & 4,66 \\
\hline 6 & $\begin{array}{l}\text { Rumah sakit } \\
\text { memiliki } \\
\text { papan } \\
\text { petunjuk } \\
\text { yang jelas }\end{array}$ & Tangible & 82,34 & A & 3,77 & 4,58 \\
\hline 7 & $\begin{array}{l}\text { Dokter } \\
\text { memberikan } \\
\text { waktu } \\
\text { pelayanan } \\
\text { yang cukup } \\
\text { memuaskan } \\
\text { pasien } \\
\end{array}$ & Empathy & 78,30 & A & 3,75 & 4,79 \\
\hline 13 & $\begin{array}{l}\text { Tenaga } \\
\text { medis dan } \\
\text { petugas } \\
\text { lainnya, } \\
\text { membantu } \\
\text { jika ada } \\
\text { permasalahan } \\
\text { pasien }\end{array}$ & $\begin{array}{c}\text { Reliabili } \\
\text { ty }\end{array}$ & 83,30 & A & 3,87 & 4,65 \\
\hline
\end{tabular}

Sumber: Pengolahan Data, 2016

\section{Potential Gain in Customer Value (PGCV)}

Untuk melengkapi hasil analisa dari Importance \& Performance, digunakan sebuah metode untuk menentukan prioritas perbaikan yang harus dilakukan oleh pihak rumah sakit. PGCV memberikan jalan bagi diagram Importance dan Performance untuk dapat dibandingkan dalam bentuk yang lebih teliti dan terperinci. berikut ini perhitungan dari keenam atribut yang berada pada kuadran A.

\section{Atribut Pernyataan 2}

1. Menghitng ACV

2. Menghitung UDCV

$=\overline{\mathrm{X}} . \overline{\mathrm{y}}$

$=3,82 \times 4,61$

$=17,58$

$=\overline{\mathrm{y}}$.Pmaks

$=5 \times 4,61$

$=23,04$

3. Menghitung indeks PGCV

$=\mathrm{UDCV}-\mathrm{ACV}$

$=23,04-17,58$

$=5,46$

Atribut Pernyataan 3

1. Menghitng ACV

$=\overline{\mathrm{X}} \cdot \overline{\mathrm{Y}}$

$=3,78 \times 4,54$

$=17,19$

2. Menghitung UDCV

$=\overline{\mathrm{y}}$. Pmaks

$=5 \times 4,54$

$=22,72$

3. Menghitung indeks PGCV

$=\mathrm{UDCV}-\mathrm{ACV}$

$=22,72-17,19$

$=5,53$

Atribut Pernyataan 4

1. Menghitng ACV

$=\overline{\mathrm{X}} \cdot \overline{\mathrm{y}}$

$=3,68 \times 4,66$

$=17,16$

2. Menghitung UDCV

$=\overline{\mathrm{y}}$.Pmaks

$=5 \times 4,66$

$=23,32$

3. Menghitung indeks PGCV

$=\mathrm{UDCV}-\mathrm{ACV}$

$=23,32-17,16$

$=6,16$

\section{Atribut Pernyataan 6}

1. Menghitng ACV

$=\overline{\mathrm{X}} \cdot \overline{\mathrm{y}}$

$=3,77 \times 4,58$

$=17,24$

2. Menghitung UDCV

$=\overline{\mathrm{y}}$. Pmaks

$=5 \times 4,58$

$=22,88$

3. Menghitung indeks PGCV

$=\mathrm{UDCV}-\mathrm{ACV}$

$=22,88-17,24$

$=5,64$

Atribut Pernyataan 7

1. Menghitng ACV

$=\overline{\mathrm{X}} \cdot \overline{\mathrm{Y}}$

$=3,75 \times 4,79$

$=17,98$

$=\overline{\mathrm{y}}$. Pmaks 
$=5 \times 4,79$

$=23,96$

3. Menghitung indeks PGCV

$=\mathrm{UDCV}-\mathrm{ACV}$

$=23,96-17,98$

$=5,98$

Atribut Pernyataan 13

1. Menghitng ACV

2. Menghitung UDCV

$=\overline{\mathrm{X}} \cdot \overline{\mathrm{Y}}$

$=3,87 \times 4,65$

$=18,00$

$=\overline{\mathrm{y}}$. Pmaks

$=5 \times 4,65$

$=23,24$

3. Menghitung indeks PGCV

$=23,24-18,00$

$=5,24$

Tabel 4 Perhitungan Indeks PGCV Kuadran A pada Diagram Kartesius

\begin{tabular}{|c|c|c|c|c|c|c|}
\hline \multirow{2}{*}{$\begin{array}{l}\text { No. } \\
\text { Per. }\end{array}$} & \multirow{2}{*}{$\begin{array}{l}\text { Perfor } \\
\text { mance } \\
(\bar{X})\end{array}$} & \multirow{2}{*}{$\begin{array}{l}\text { Impor } \\
\text { tance } \\
(\overline{\mathbf{y}})\end{array}$} & $\begin{array}{l}\text { Nilai } \\
\text { ACV }\end{array}$ & $\begin{array}{l}\text { Nilai } \\
\text { UD } \\
\text { CV }\end{array}$ & \multirow{2}{*}{$\begin{array}{l}\text { In } \\
\text { deks } \\
\text { PG } \\
\text { CV }\end{array}$} & \multirow{2}{*}{$\begin{array}{l}\text { Uru } \\
\tan \\
\text { Ke }\end{array}$} \\
\hline & & & $\overline{\mathrm{X}} . \overline{\mathrm{y}}$ & $\begin{array}{l}\bar{y} . \mathrm{P} \\
\text { maks }\end{array}$ & & \\
\hline 2 & 3,82 & 4,61 & 17,58 & 23,04 & 5,46 & 5 \\
\hline 3 & 3,78 & 4,54 & 17,19 & 22,72 & 5,53 & 4 \\
\hline 4 & 3,68 & 4,66 & 17,16 & 23,32 & 6,16 & 1 \\
\hline 6 & 3,77 & 4,58 & 17,24 & 22,88 & 5,64 & 3 \\
\hline 7 & 3,75 & 4,79 & 17,98 & 23,96 & 5,98 & 2 \\
\hline 13 & 3,87 & 4,65 & 18,00 & 23,24 & 5,24 & 6 \\
\hline
\end{tabular}

Sumber: Pengolahan Data, 2016

Berdasarkan Tabel 4.16 dapat diketahui perbaikan pertama yang harus dilakukan yaitu atribut pernyataan 4 (Ruangan di rumah sakit memiliki peralatan yang lengkap), kedua yaitu atribut pernyataan 7 (Dokter memberikan waktu pelayanan yang cukup memuaskan pasien), ketiga yaitu atribut pernyataan 6 (Rumah sakit memiliki papan petunjuk yang jelas), keempat yaitu atribut pernyataan 3 (WC Rumah sakit bersih), kelima yaitu atribut pernyataan 2 (Rumah sakit memiliki ruang tunggu yang nyaman) dan keenam yaitu atribut pernyataan 13 (Tenaga medis dan petugas lainnya, membantu jika ada permasalahan pasien).

\section{Kesimpulan}

Berdasarkan hasil pengolahan data yang telah dilakukan maka dapat diambil kesimpulan bahwa kepuasan konsumen/pasien rawat inap RSUD Tengku Rafi'an Kabupaten Siak belum sepenuhnya sesuai dengan kepentingan atau harapan pasien/konsumen. Berdasarkan metode Importance Performance Analysis atribut-atribut yang menjadi prioritas utama untuk dilakukan perbaikan atau yang berada pada kuadran A yaitu ruangan di rumah sakit memiliki peralatan yang lengkap, dokter memberikan waktu pelayanan yang cukup

memuaskan pasien, rumah sakit memiliki papan petunjuk yang jelas, WC rumah sakit bersih, rumah sakit memiliki ruang tunggu yang nyaman dan tenaga medis dan petugas lainnya membantu jika ada permasalahan pasien.

Perhitungan dengan menggunakan Potential Gain in Customer Value (PGCV) menghasilkan urutan prioritas perbaikan layanan pada kuadran A yaitu ruangan di rumah sakit memiliki peralatan yang lengkap, dokter memberikan waktu pelayanan yang cukup memuaskan pasien, rumah sakit memiliki papan petunjuk yang jelas, WC Rumah sakit bersih, rumah sakit memiliki ruang tunggu yang nyaman dan tenaga medis dan petugas lainnya membantu jika ada permasalahan pasien.

\section{DAFTAR PUSTAKA}

Gasperz, V. Total Quality Management. Gramedia Pustaka Utama. Jakarta : 2002.

Gasperz, V. Manajemen Kualitas dalam Industri Jasa. Gramedia Pustaka Utama. Jakarta : 2002.

Handriati, A. A., Sunario, dan Helia, V. N. Analisis Kualitas Pelayanan Publik Terhadap Kepuasan Konsumen dengan Menggunakan Metode Servperf-IPACSI. Jurnal Jurusan Teknik Industri Fakultas Teknologi Industri Universitas Islam Indonesia, Vol.21 No.4 Halaman 178-190. Yogyakara : 2015.

Hasan, M. I. Pokok-pokok Materi Statistik 2 (Statistik Inferensif). PT. Bumi Aksara. Jakarta : 2010.

Kotler, p, Marketing Management. Millennium Edition. New Jersey. Prentice Hall International, Inc : 2006.

Kula, J. I. Metode Penetapan Biaya Rawat Inap pada Blu RSUP Prof.Dr.R.D. Kandou Manado. Jurnal Fakultas Ekonomi dan Bisnis Jurusan Akuntansi Universitas Sam Ratulangi, Vol.1 No. 3 ISSN:23021174 Halaman 793-803. Manado : 2013.

Lestari, E., Tania, K. D., dan Rahmi, L. Sistem Informasi Rekam Medik Pada Rumah Sakit Bersalin Graha Rap Tanjung Balai Karimun. Jurnal Jurusan Sistem Informasi Universitas Sriwijaya, Vol.3 No.2 Halaman 388-397. Palembang: 2011. 
Liu, MC. "The Multi Dimensionaland Hierarchical Structure of Perceived Quality and Customer Satisfaction", International Journal of Management, Vol 22, No. 3 : 2005.

Mulyono, B. H., Yoestini, Nugraheni, R., dan Kamal, M. Analsis Pengaruh Kualitas Produk dan Kualitas Layanan Terhadap Kepuasan Konsumen (Studi Kasus pada Perumahan Puri Mediterania Semarang). Jurnal Jurusan Manajemen Fakultas Ekonomi dan Bisnis Universitas Diponegoro. Vol.4 No.2 Halaman 92100. Semarang : 2007.

Nugraha, R., Harsono, A., dan Adianto, H. Usulan Peningkatan Kualitas Pelayanan Jasa pada Bengkel X berdasarkan Matrix Importance Performance Analysis (Studi kasus di Bengkel AHASS PD. Sumber Motor Karawang). Jurnal Jurusan Teknik Industri, Institut Teknologi Nasional (Itenas). Vol.01 N0.03 ISSN:2338-5081. Bandung : 2014.

Purwanti, N. D., Sugiono, dan Hardiningtyas, D. Analisis Kualitas Pelayanan dan Citra Perusahaan Terhadap Kepuasan dan Loyalitas Pelanggan. Jurnal Jurusan Teknik Industri, Universitas Brawijaya. Vol. 3 No. 2. Malang : 2015.

Ramadhani, A. F., Harsono, A., dan Adianto, H. Usulan Peningkatan Kualitas Pelayanan Jasa Rumah Sakit Ibu dan Anak dengan Menggunkan Metode Potential Gain in Customer Value. Jurnal Jurusan Teknik Industri, Institut Teknologi Nasional (Itenas). Vol.01 No.04 ISSN:2338-5081. Bandung : 2014.

Saragih, R., Lubis, A.N., dan Sutatniningsih, R. Pengaruh Mutu Pelayanan Kesehatan Terhadap Loyalitas Pasien Rumah Sakit Umum Herna Medan. Jurnal Jurusan Ilmu Kesehatan Masyarakat FKM USU, Medan : 2013.

Siregar, S., F. Analisis Tingkat Kualitas Pelayanan dengan Metode Index Potential Gain In Customer Value (PGCV) di PT Bank Muamalat Indonesia Cabang Medan. Jurnal Staf Pengajar Jurusan Teknik Kimia, Fakultas Teknik USU, Volume 7 No.4. Medan : 2006.
Tjiptono, F dan Diana, A. Total Quality

Management. Edisi Revisi, ANDY.

Yogyakarta : 2003.

Umar, H. Metode Riset Bisnis. PT. Gramedia

Pustaka Utama, Jakarta : 2002.

Wijaya, T. Manajemen Kualitas Jasa. Permata Putri Media J1. Topas Raya C2 No.16 Kembangan, Jakarta Barat : 2011. 